\title{
Experimental Study of Paraffin Wax-Copper Nanoparticles Thermal Storage Material
}

\author{
Ali Lateef Tarish ${ }^{1}$, Naseer T. Alwan ${ }^{2}$ \\ Asst. Lecture, Thermal Mechanics, Eng. Dept., Southern Technical University, Basra, Iraq \\ Asst. Lecture, Refrigeration and A/C, Eng. Dept., Northern Technical University, Kirkuk, Iraq
}

*Corresponding Author: Ali Lateef Tarish, Asst. Lecture, Thermal Mechanics, Eng. Dept., Southern

Technical University, Basra, Iraq

\begin{abstract}
In this experimental study a test was carried out on a paraffin wax-copper (PWC) thermal property, which consists of a phase change material with $10 \%$ copper powder. The PCW with rectangular shape $(25 \mathrm{~cm} \times 25 \mathrm{~cm} \times 30 \mathrm{~cm})$ size is supplied with heater within it, and installed inside an isolated tank case, which allows the water to flow over the PWC from inlet side to the outside. This sample is used as a thermal storage .The PWC is initially heated by electric heater reaching phase liquid at Temp $\left(90^{\circ} \mathrm{C}\right)$ whereas the supply water temperature ranged $\left(19-20^{\circ} \mathrm{C}\right)$. An engineering equation solver (EES) pc program has been created to register the parameters (outlet water Temp; heat transfer rate, and the time needs to release total the thermal energy). The outcomes showed that outlet water Temp gained due to thermal storage in the water tank $(P W C)$ is more than with (PCM) which comprises of paraffin wax without copper powder. The water temperature decreases with the increase of water flow rate of mass and the freeze time for the sample takes a long time period for lower flow rate of mass. The ratio of the thermal storage for mixture paraffin wax increased by $30.7 \%$ compared with a normal wax pure.
\end{abstract}

Keywords: paraffin wax-copper, supply water temperature, mass flow rate.

\section{INTRODUCTION}

\subsection{Background}

The thermal energy storage is the transitory saving of high-temperature or low-temperature energy to use later. It connects the gap amid the demands and actual energy use. The used thermalstoragemay include many hours'storage cycles which depend on the systems requirements design. Whereas the output constantly thermal, while the input may be either electrical or thermal. The PCM is a product that saves and releases thermal energy through melting and freezing process. When those material freezing, it will release a large amount of energy in form latent heat of fusion. Conversely, when the material is melted, an equal amount of energy is absorbed from surrounding when it converts from solid to liquid phase. PCM between $C 5 \& C 15$ are liquids, and all others are solids waxy. The mainly use of Paraffin is commercial thermalstorageorganic. It contains a straight of a hydrocarbon chain, which has melting Temp in a range $\left(23-670^{\circ} \mathrm{C}\right)$. The commercial PCM obtained from distillation the petroleum and it; not a net substance but it's a combination of different hydrocarbons[1].

They are suitable for all metals containers and easily combined into thermal storage systems, Commercial paraffin used in the present work had been used by large numbers of the investigation, it melts at around $\left(55^{\circ} \mathrm{C}\right)$, and has a latent heat of melting at a range $(210 \mathrm{KJ} / \mathrm{Kg})$. When selecting a PCM for particulars, operating or cooling process should agree with the transmission Temp [2].

\subsection{Research Article}

Belen Zalma and et. al [3] conducted a review of the history of thermal energy storage with solidliquid phase changes. Three aspects materials, heat transfer, and applications which contain over 150 materials were used in research as PCMs. Ukrainczyk and et. al[4] reported an experimental investigation of thermal properties for five paraffin waxes in order to evaluate their potential use as a 
phase change material. The interference of the phase transition process has been indicated as a probable explanation of large differences in solid thermal conductivity and non-monotonic temperature. Pathik Himanshu[5],carried out experimental to investigate a process of enhancing the thermal conductivity of paraffin wax by making use of porosity high open foams metal. The effect of copper metal foam on heat transfer during melting and solidification was analyzed by determining Coefficient of heat transfer by convection. The results showed that thermal conductivity of PCM was increased by16 - 18timesas compared to the pure paraffin wax. Marte Stubsjoen [6], established the applicability of five models of efficient thermal conductivity to determine the effective thermal conductivity for paraffin wax deposit which has been evaluate according to structure of deposit. The results showed that the temperature of the deposit surface increased with the increase in wax deposit thickness. The results indicated reduce the rate growth of wax layer with time and needs to dynamic simulations to avoid prediction of wax deposit thickness. Miqdam Chaichan and et.al[7], presented an experimental investigation on enhancing the thermal conductivity of paraffin wax using two high conductivity materials. Alumina $\left(\mathrm{A}_{12} \mathrm{O}_{3}\right)$ and $\left(\mathrm{T}_{\mathrm{i}} \mathrm{O}_{2}\right)$ nanoparticles were added in a mass fraction of $1,2,3,4$ and $5 \%$ in Iraq paraffin wax. The results indicate that the paraffin wax conductivity increased with increase in the nanoparticles mass fraction. The charging and discharging rates of thermal energy enhanced significantly by adding nanoparticles to paraffin wax compared to net paraffin as PCM. Miqdam Chaichanand Hussien Kazem[8], investigated the enhancement heat transfer of paraffin wax which existent in a single slope solar distiller base and sides. Aluminum powder was added to paraffin wax to enhance its thermal conductivity. The results showed that the aluminum powder improve phase change materials showed enhanced of thermal conductivity in comparison to the phase materials. Adding aluminum powder to PCM increased as stiller productivity as well as increasingtime of distillation. JaumeGasia[9], carried out experimental study of thermal behavior of commercial wax with melt Temp at $\left(58^{\circ} \mathrm{C}\right)$ is resolve as a phase change material (PCM)candidate for manufacturing waste heat recovery. The results from pilot plant which analysis allowed understanding the various methods of heat transfer in real charging and discharging process as well as the effect of the geometry of tank on energy transferred and time required for charging and discharging processes.

\subsection{Objectives of the Present Work}

By reviewing previous studies, we noticed that none of those studies had added copper particles to paraffin wax. In this paper $10 \%$ of copper is added for purpose of increasing the thermal conductivity of paraffin wax moreover increasing thermal storage during evacuation and reduce time needed for charging by using temperature. Thermal storage was calculated using heat transfer between Paraffin wax and water.

\section{EXPERIMENTAL SETUP}

Experimental system as shown in (Fig.1), it consists of three essential parts, which are:

1.The storage unit which consist of a phase change material (PCM) or a phase change material with $10 \%$ copper powder $(\mathrm{PWC})$ of size $(25 \mathrm{~cm} \times 25 \mathrm{~cm} \times 30 \mathrm{~cm})$, the PCM or PWC with rectangular shape supplied with heater within it, and installed inside isolated a tank case which allows the water to flows over the paraffin wax from inlet side to the outlet side. The initial temperature of the PWC or PCM is $\left(27^{\circ} \mathrm{C}\right)$. That unit works to achieve two aims which are to absorb and store thermal energy.

2. The water tank is used to supply water to the unit through connected pipes and globe valve to control the amount of water supplied to the unit.

3. Measurement and control system, which consist of:

a) A rotmeter: a device to measures the flow rate of water in a closed tube.

b) Thermocouples type $[\mathrm{k}]$ with diameter of $(0.3 \mathrm{~mm})$ (Fig.2): to measure temperatures at different points. It has been calibrated according to the specifications and temperature ranges $\left(0-100^{\circ} \mathrm{C}\right)$. 


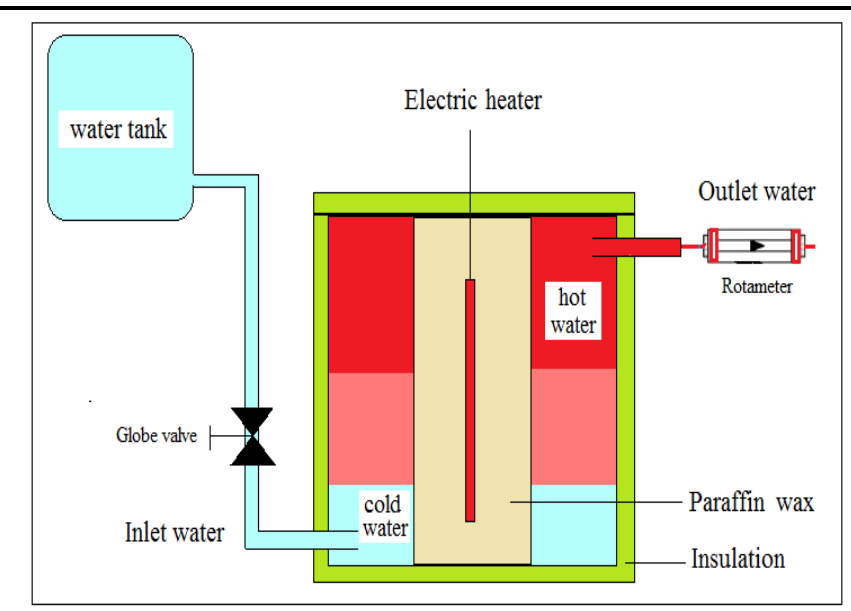

Fig1. A cross section for the experimental system.

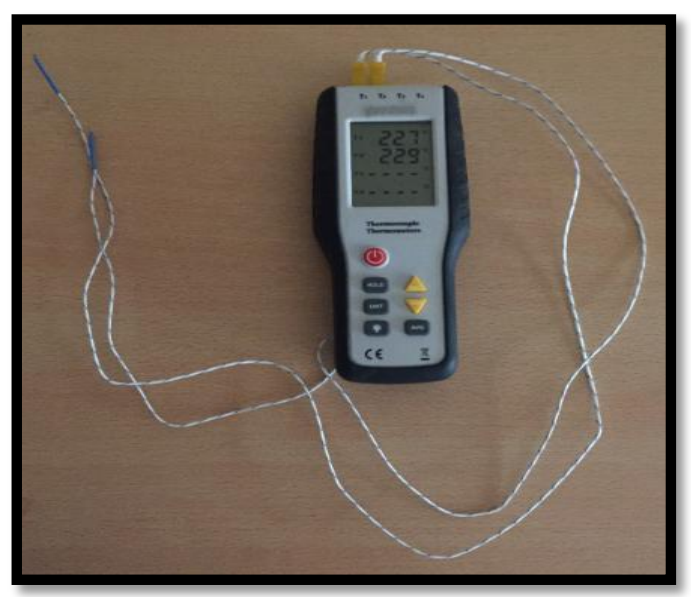

Fig2. Temperature measurement device.

\subsection{Procedures of the Experimental}

Figure (3) below shows a flow chart of the procedure of the experiment:

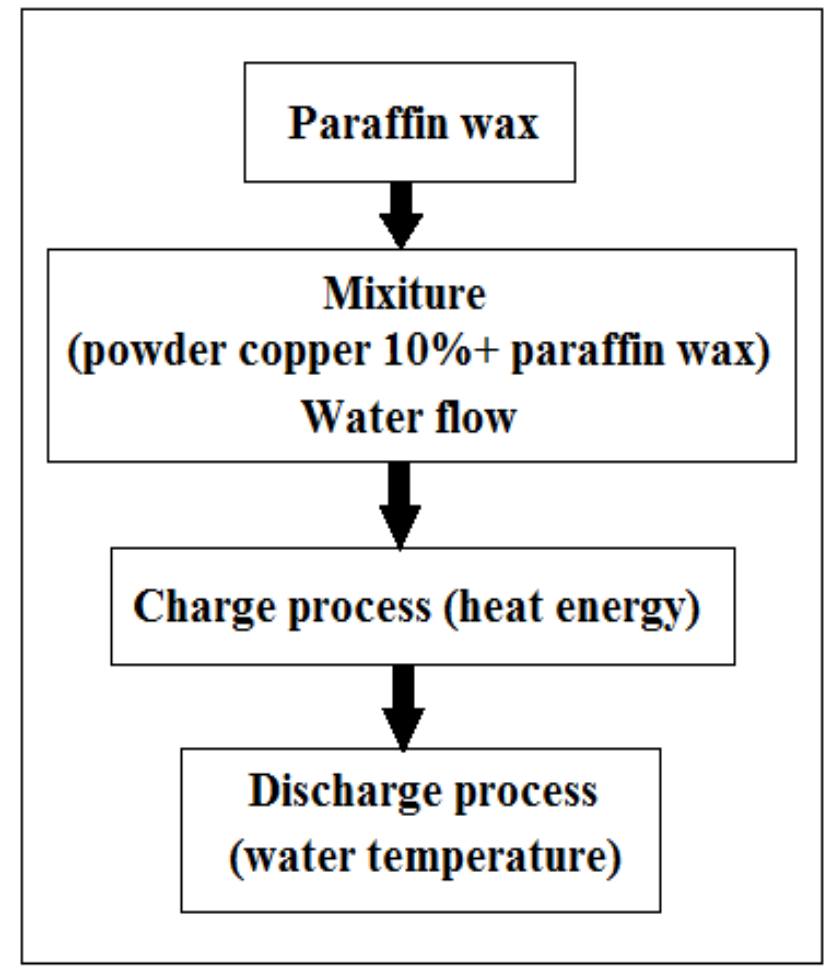

Fig3.Steps of the experiment

\section{Physical Model}

\subsection{Assumptions}

1. Heat transfer is both conduction and convection.

2. The water flow is Newtonian, incompressible and laminar.

3. The physical properties of PWC depends on the temperature.

4. Variation of volume is neglected during phase change.

\subsection{Governing Equation}

To overcome the low of thermal conductivity of paraffin wax, $10 \%$ of copper powder which has been added to it to improve has conductivity. The powder copper particles have been considered as $(70 \mu \mathrm{m})$,physical properties for the mixture calculate as follows[10]: 
Thermal Conductivity of compound is :

$k_{m i}=\left(k_{p . w} \times v_{p . w}\right)+\left(k_{c} \times v_{c}\right)$

where $v_{p . w}=\frac{V_{p . w}}{V_{m i}}, \quad v_{c}=\frac{V_{c}}{V_{m i}}$

The specific heat of the compound is:

$C p_{m i}=\left(C p_{p . w} \times m_{p . w}\right)+\left(C p_{c} \times m_{c}\right)$

where $m_{p . w}=\frac{M_{p . w}}{M_{m i}}, \quad m_{c}=\frac{M_{c}}{M_{m i}}$

The thermal conductivity of the compound is:

$\rho_{m i}=\left(\rho_{p . w} \times v_{p . w}\right)+\left(\rho_{c} \times v_{c}\right)$

The paraffin density and viscosity depend on temperature [11]

$\rho_{p . w}=\frac{750}{0.001 \times(T-319.15)+1}$

$\mu_{p}=0.001 \times \exp \left(-4.25+\frac{1700}{T}\right)$

The water proprties taken at $T_{w}=\frac{\left(T_{w o}+T_{w i}\right)}{2}$

The heat transfer rate for water [12]

$Q_{w}=\dot{m} \times C p_{w} \times\left(T_{w o}-T_{w i}\right)$

\section{RESUltS AND DISCUSSIONS}

An EES PC program had been developed to compute the parameters (outlet water Temp; heat transfer rate, time required to release all the heat energy). Experiments were conducted with mass flow rate of water of range $(0.5-0.7) \mathrm{m}^{3} / \mathrm{min}$, with inlet temperature of the water supply of $\left(19-20^{\circ} \mathrm{C}\right)$ over the rectangular PWC, and the ambient temperature $\left(25^{\circ} \mathrm{C}\right)$. During the charging process the water were continuously supplied over the PCM reservoir. Initial Temp of PWC was $\left(27^{\circ} \mathrm{C}\right)$, and Electric Heater exchanges its thermal energy to PWC, a PWC heated up to melting Temp(saving energy as a sensible heat). After that, the heat stored as latent heat, thus the PWC melts and becomes liquids phase. Then the energy saved as sensible heat as a liquids phase PWC. The Temp PWC is registered at a period of 13 minutes. The charge process is continued PWC Temp reaches to the maximum Temp at $\left(90^{\circ} \mathrm{C}\right)$, in this time the thermal energy saved in PWC is transferred to the water tank so the temperature of water cold is increased. An experimental result for discharging process with average flow rate of $\left(0.5 \mathrm{~m}^{3} / \mathrm{min}\right)$.are shown in Fig. 4 . As shown the PCM temperature $\left(\mathrm{T}_{\mathrm{P}}\right)$ decreased gradually and took $(65$ minutes) to decrease $50^{\circ} \mathrm{C}$. Fig. 5 shownimpactof flow rate of mass on outlet water Temp. As shown increasing flow rate of mass will decrease outlet water Temp.

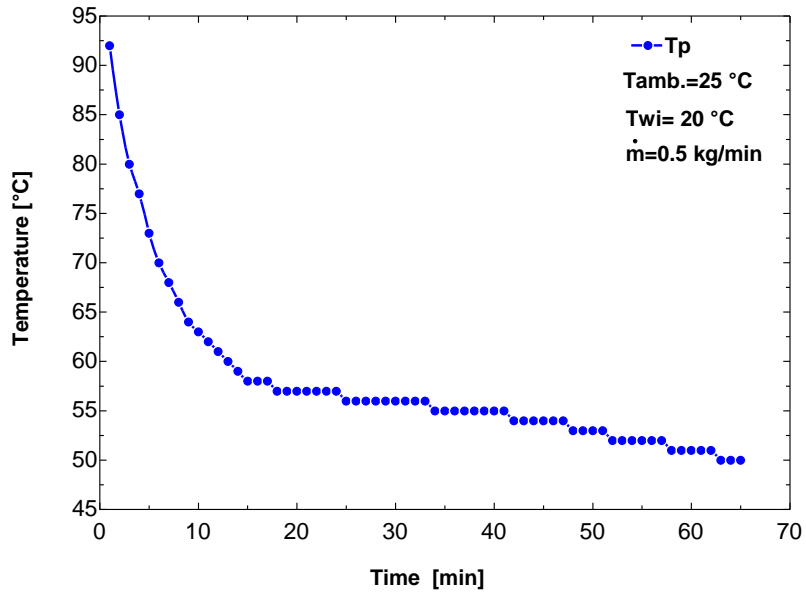

Fig4. Variation temperature PCM with time during discharging mode of an average flow rate $\left(0.5 \mathrm{~m}^{3} / \mathrm{min}\right)$.

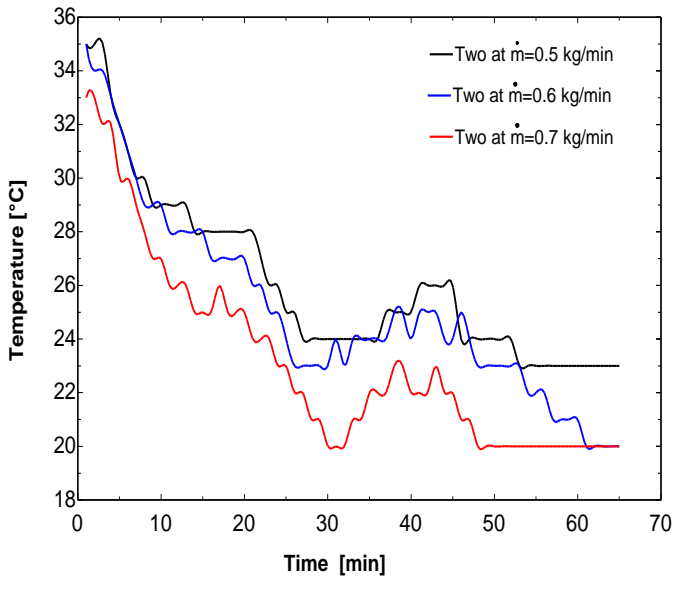

Fig5. Out let water temperatures against time discharge withvarious flow rates of mass. 
Fig.6shows the relation between heat stored in PWC and discharge time when flow rate of mass is $(0.5 \mathrm{~kg} / \mathrm{min})$. It is observed that the heat stored at $(0.5 \mathrm{~kg} / \mathrm{min})$ is reduced with time until it become (60 watts) after 65minutes.The Fig.7 shows the Thermal conductivity during charging time enhancement caused by adding $10 \%$ of Copper Nanoparticles (PWC).Fig.8 shows the comparison between the temperatures gained due to thermal storage in paraffin wax-copper (PWC) and the temperatures gained due to thermal storage in a phase change material (PCM) .Results show the thermal storage in paraffin wax-copper (PWC) are more than that in a phase change in pure material (PCM). The Fig.9 shows the comparison between the temperatures between water output discharge time for PCM and PWC. .Results shows the temperatures of water output in paraffin wax-copper (PWC) are more than in case of a phase change pure material (PCM).

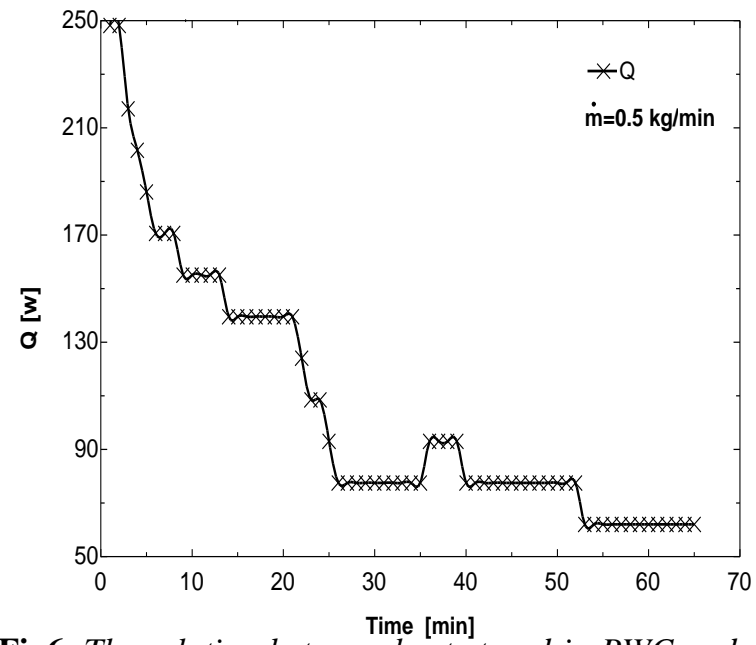

Fig6. The relation between heat stored in PWC and discharge time

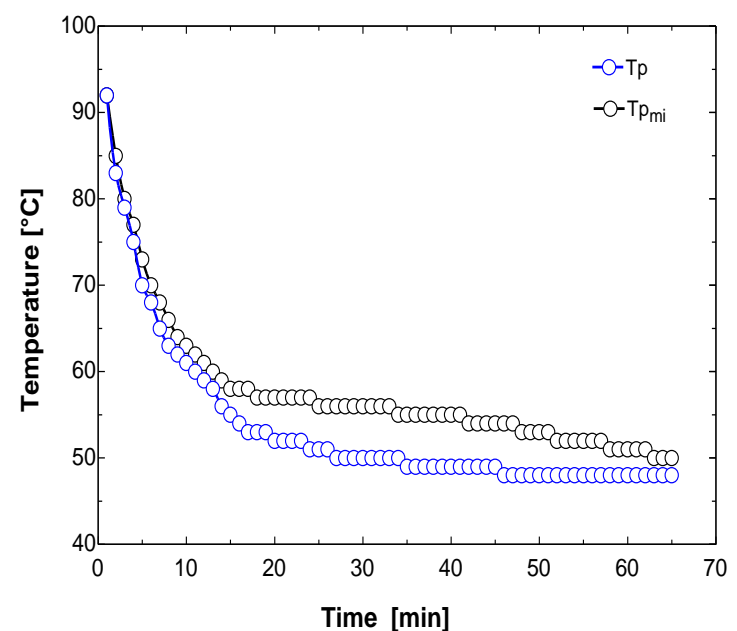

Fig8. The relation between the temperatures gained due to thermal storage and discharge time for PCM and $P W C$

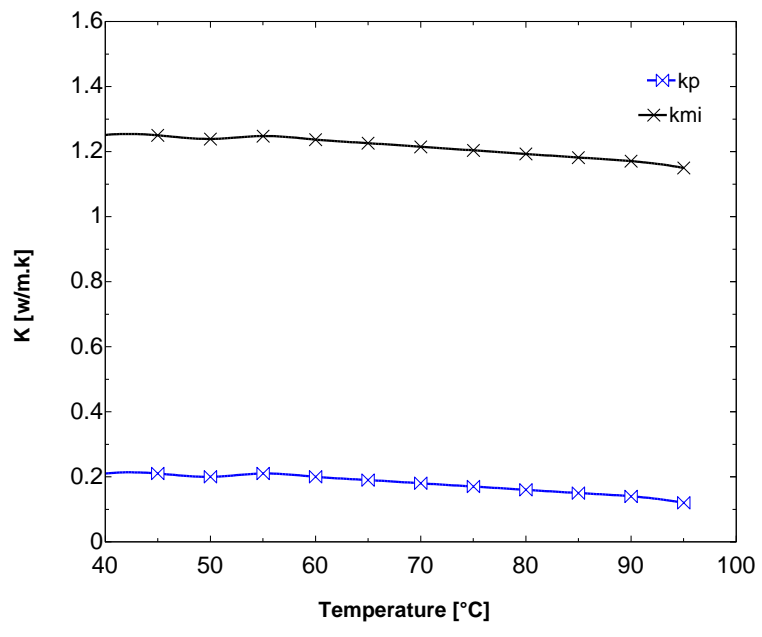

Fig7. Thermal conductivity and temperature for $P C M$ and $P W C$

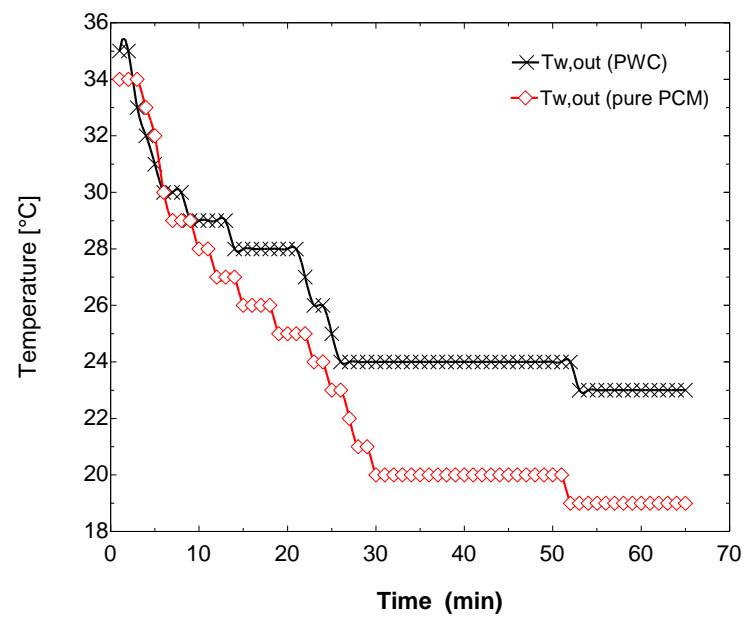

Fig9. The relation between the temperatures of water output and discharge time for PCM and PWC.

\section{Conclusion}

1. The amount of change in thermal energy upon discharge is less than the charging process due to the difference between the heat transfer coefficient during the melting and freezing process of paraffin wax.

2. The ratio of the thermal storage for mixture paraffin wax increased by $30.7 \%$ compared with a normal wax pure when mixing ratio of $10 \%$ and the results were comparable to those presented in reference [13].

3. The value of thermal storage is equal to zero for the pure paraffin at 56- minutes, while the value of storage equal to 2.07 watts for the same time. 
4. The effectiveness of the thermal storage are in the best condition at the specified time (1-21 minutes), where the degree of outside water temperature is $\left(28^{\circ} \mathrm{C}\right)$, as it shown in table below. Consequently it's recommended that charging is conducted every 20 minutes.

\begin{tabular}{|c|c|c|c|}
\hline Charge time & Tw,in & Tw,o & Discharge time \\
\hline 4 min & $19{ }^{0} \mathrm{C}$ & $35-28{ }^{\circ} \mathrm{C}$ & $20 \min$ \\
\hline
\end{tabular}

5. Wax freezing process increase $23.4 \%$ when the water flow rate is increase from 0.5 to $0.7 \mathrm{~kg} / \mathrm{min}$.

6. Higher paraffin wax temperature results in the lower thermal conductivity as the amount of thermal conductivity to pure paraffin wax equal to $0.09 \mathrm{~W} / \mathrm{m} . \mathrm{k}$ when the temperature is reduced from 95-40 degrees Celsius but the mixture wax the amount of change is equal to 0.101 at the same temperatures and the results were comparableto those in research [14].

7. The total thermal conductivity gained is $83.2 \%$ at a temperature of $\left(40^{\circ} \mathrm{C}\right)$ and $89.3 \%$ at a temperature of $\left(95^{\circ} \mathrm{C}\right)$.

\section{LIST OF SYMBOLS}

\begin{tabular}{|c|l|c|l|}
\hline English symbols: & & Subscripts: & \\
\hline$C p$ & Specific heat $\left(\mathrm{kJ} / \mathrm{kg} .{ }^{\circ} \mathrm{C}\right)$ & $c$ & Copper \\
\hline$K$ & Thermalconductivity $\left(\mathrm{w} / \mathrm{m} .{ }^{\circ} \mathrm{C}\right)$ & $w$ & Water \\
\hline$L$ & Length $(\mathrm{m})$ & $m i$ & Surface \\
\hline$W$ & Width $(\mathrm{m})$ & $i$ & Mixture \\
\hline$v$ & Volume friction(-) $\left.^{3}\right)$ & Inlet \\
\hline$V$ & \left.${\text { Volume }\left(\mathrm{m}^{3}\right)}\right)$ & Outlet \\
\hline$M$ & Mass friction $(-)$ & $P W$ & \\
\hline$m$ & Mass $(\mathrm{kg})$ & $P W C$ & Paraffin Wax \\
\hline$A$ & Area $\left(\mathrm{m}^{2}\right)$ & $P C M$ & Paraffin wax copper \\
\hline$h$ & Heat transfercoefficient $\left(\mathrm{w} / \mathrm{m}^{2} . \mathrm{C}\right)$ & $P r$ & Phase change material \\
\hline$Q$ & Heat transfer $(\mathrm{w})$ & $N u$ & Prandl number \\
\hline$m^{\circ}$ & Mass flow rate $(\mathrm{kg} / \mathrm{sec})$ & $R e$ & Reynolt number \\
\hline & & & \\
\hline
\end{tabular}

\section{REFERENCES}

[1] Thirugnanam and Marimuthu " Experimental Analysis of Latent Heat Thermal Energy Storage using Paraffin Wax as Phase Change Material" International Journal of Engineering and Innovative Technology(IJEIT) Volume 3, Issue 2, PP.372-376, 2013.

[2] Ettouney and et. Al. "Study of the performance of Paraffin Wax as a Phase Change Material in Paked Bed Thermal Energy Storage System "Energy convers manage, 2006.

[3] Belen Zalma and et.al " Review on thermal energy storage with phase change: materials, heat transfer analysis and applications" Applied Thermal Engineering PP.251-283, 2003.

[4] Ukrainczyk and et.al "Thermo physical Comparison of Five Commercial Paraffin Waxes as Latent Heat Storage Materials" Chem. Biochem. Eng.Q.24 (22) PP.129-137, 2010.

[5] PathikHimanshu "Thermal Energy Storage in Copper Foams filled with Paraffin Wax "master thesis, University of Toronto, Mechanical \& Industrial Engineering, 2010

[6] MarteStubsjoen "Analytical and Numerical Modeling of Paraffin Wax in Pipelines" master thesis, Norwegian University of Science and Technology, Department of Petroleum Engineering and Applied Geophysics, 2013.

[7] MiqdamChaichan and et.al "Thermal conductivity enhancement by using nano material in phase change material for latent heat thermal energy storage systems"saussur EAISSN: 0373-2525 Vol.5 (6): PP 48-55, 2015.

[8] MiqdamChaichan and HussienKazem" Using Aluminum Powder with PCM (Paraffin Wax) to Enhance Single Slope Solar Water Distiller Productivity in Baghdad-Iraq Winter Weathers" International journal of renewable energy research, Vol. 5, No. 1, PP.251-257, 2015.

[9] JaumeGasia " Evaluation of a Praffin as Phase Change Material fotr Thermal Energy Storage in Laboratory Equipment and a shell-and-Tube Heat Exchager Applied sciences, www. Mdpi.com/journal/applsci, PP.1-12, 2016.

[10] Alkilani Mahmud, Sopian K, Alghoul M. A. and Mat Sohif" Using a paraffin wax aluminum compound as a thermal storage material in a solar air heater " Journal of Engineering and Applied Sciences, Vol. 4, No. 10, PP. 74-77, 2009. 
[11] Auriemma and Iazzetta"Numerical Analysis of Melting of Paraffin Wax with $\mathrm{AL}_{2} \mathrm{O}_{3}, \mathrm{ZnO}$ and $\mathrm{CuO}$ Nanoparticles in Rectangular Enclosure" Indian Journal of Science and Technology, Vol. 9, PP. 1-12, 2016.

[12] Yunus "Heat transfers a practical Approach" $2^{\text {nd }}$ edit 2008.

[13] Lubna A. Naeem, Tahssen A. AL-Hattab and Majid I. abdulwahab " Heat transfer enhancement in energy storage in spherical capsules filled with paraffin wax and beads" Iraqi Journal of Chemical and Petroleum Engineering, Vol. 17 No. 4 (December 2016) 25-33.

[14] BaydaaJaberNabhan " Using Nanoparticles for Enhance Thermal Conductivity of Latent Thermal Energy Storage" Journal of Engineering Number No. 6, Vol. 21,(June 2015) 37-55.

Citation: Ali Lateef Tarish \& Naseer T. Alwan (2017). Experimental Study of Paraffin Wax-Copper Nanoparticles Thermal Storage Material, International Journal of Modern Studies in Mechanical Engineering (IJMSME), 3(3), pp.11-17 DOI: http://dx.doi.org/10.20431/2454-9711.0303002

Copyright: () 2017 Ali Lateef Tarish This is an open-access article distributed under the terms of the Creative Commons Attribution License, which permits unrestricted use, distribution, and reproduction in any medium, provided the original author and source are credited 